\section{A consumption timecycle: contextually situated and temporally recurring experiences}

Temporally recurring experiences

\author{
Toni Ryynänen
}

Ruralia Institute, University of Helsinki, Mikkeli, Finland and

Helsinki Institute of Sustainability Science (HELSUS), University of Helsinki, Helsinki, Finland, and

Visa Heinonen

The Centre for Consumer Society Research, University of Helsinki, Helsinki, Finland
Received 6 February 2020 Revised 21 April 2020 4 June 2020 Accepted 4 June 2020

\begin{abstract}
Purpose - Temporal consumption experiences have been conceptualised as universal, subjective or practice-based experiences. Little research, though, addresses such experiences in conjunction with the repeated and situational consumption events that bring them about. The purpose of this paper is to extend current knowledge by examining how the temporal and situational intertwine during consumption events. For this purpose, the concept of a consumption timecycle based on the research data is constructed.

Design/methodology/approach - The paper takes a longitudinal and researcher-led approach to study temporal consumption experiences. The data was collected through participant observations, video recordings and personal subjective introspections during three consecutive annual Nordic motorcycle consumer trade shows (2014-2016). The data was analysed using an interpretive approach.

Findings - The results demonstrate five temporalities that characterise a consumption timecycle as follows: emerging, core, intensifying, fading and idle-time temporalities. The features of these temporal experiences are presented in the conclusions section of the paper.

Research limitations/implications - Recalled temporal experiences are mediated experiences and they differ from lived experiences. The transferability or generalisability of the results might be limited, as the case is situated in the Nordic context.

Originality/value - The paper presents the novel concept of a consumption timecycle that extends current debates about consumer time. The consumption timecycle is contrasted with established temporal concepts in consumer and marketing research.
\end{abstract}

Keywords Consumption, Time, Observation, Consumer trade show, Subjective introspection, Timecycle

Paper type Research paper

\section{Introduction}

Time and temporality have a constant, yet implicit, impact on consumers' thinking, behaviour and everyday practices. Perceptions of time and various time conceptions are internalised from an early age and embedded in people's behaviour and they frame all aspects of our lives. Time differentiates mutually exclusive profane and sacred domains, as

(C) Toni Ryynänen and Visa Heinonen. Published by Emerald Publishing Limited. This article is published under the Creative Commons Attribution (CC BY 4.0) licence. Anyone may reproduce, distribute, translate and create derivative works of this article (for both commercial and noncommercial purposes), subject to full attribution to the original publication and authors. The full terms of this licence may be seen at http://creativecommons.org/licences/by/4.0/legalcode
Qualitative Market Research: An International Journal Vol. 24 No. 2, 2021 pp. $221-239$ pp. $221-239$
Emerald Publishing Limited 1352-2752 DOI 10.1108/QMR-02-2020-0024 
QMR 24,2 well as the private and public spheres of life, which follow physiotemporal, biotemporal or sociotemporal patterns (Zerubavel, 1981). Instead of a single and clear conception of time, people tend to have several flexible and overlapping views on the passing of time. Temporal experiences have no objective reality independent of human beings. Time is a socially negotiable and culturally contested concept: time can be experienced as circular, seasonal, linear or segmented, as being oriented towards the future, instantaneous or representative of a longer period (Bergadaà, 2007). These temporal experiences also tend to become intertwined in people's everyday lives.

The purpose of this article is to examine the interplay between temporal and situational elements of consumption. For this purpose, we construct the concept of a consumption timecycle based on the qualitative research data. We define a consumption timecycle as the temporal interrelation between recurring consumption events and the related experiences. A consumption timecycle describes repeating consumption events, which are temporally situated within a specific context and shaped by the consumer's experiences before, during and after an event. A consumption timecycle recurs and can be used to describe consumption events that exhibit time and situational constraints and a chain of unfolding consumption experiences related to temporally framed events organised at restricted physical sites and limited in their accessibility. We connect the concept of a consumption timecycle to consumers' temporal experiences about repeating events rather than to universal time conceptions and cultural explanations or to an individual's particular timestyles.

To understand consumers' actions and behaviours regarding time, it is necessary to examine the temporal and contextual relationships impacting consumption events and how they are experienced. The study extends current discussions about time and temporality in consumer and marketing research by examining recurring consumption events within the context of annual Nordic consumer motorcycle trade shows. We conducted a multiyear, same-sited qualitative data collection and comparative case analysis of temporal experiences to construct the concept of timecycle. Our research methodologies included participant observation and introspection. We worked in the field as two participant observers with different backgrounds in terms of previous participation in the motorcycle trade shows and in the motorcycle subculture of consumption (Schouten and McAlexander, 1995). The first author is a motorcycle enthusiast and regularly visited the show during the 2000s. The second author had no prior experience with motorcycles and visited the show for the first time in 2014 when the material collection process began.

Extant studies on consumer time have covered objective and subjective perspectives, but they have seldom examined temporal experiences taking place before and after a consumption event. The temporal experiences taking place between recurring consumption events shape how consumers recall past events and how they perceive a forthcoming consumption event. Another research gap concerns the lack of longitudinal studies examining the temporal experiences of recurring consumption events. Our article contributes to these knowledge gaps by providing a theoretical understanding of temporal experiences and by proposing a novel approach consistent with existing concepts of consumer time.

Our approach has its limitations, presented together with the conclusions and the consumption timecycle concept in Section 5. The results of the study and composition of consumption timecycle are discussed in Section 4. In addition to the justifications for our etic research approach, the qualitative data, ranging from participant observations and video footage to the researchers' subjective personal introspections and written fieldnotes, are introduced in Section 3. Before presenting our data and the analysis procedure, the existing 
literature on the temporality of consumption is reviewed to build a context for inquiry, as prior studies have emphasised the significance of intertwining temporal and situational factors in consumption experiences in Section 2 (Askegaard and Linnet, 2011; Lindberg and Eide, 2016; Lindberg and Østergaard, 2015; Walls et al., 2011a, 2011b).

\section{Time and temporality in consumer research}

Studies on the temporal dimensions of consumption emerged in consumer and marketing research as early as the late 1960s (for a review of earlier studies on time, see Jacoby et al., 1976). The distant echoes from more than 40 years ago can still be heard, as researchers have recently called for a unified theoretical anchoring of the concept of consumer time. However, with time being such a broad topic, others have proposed decompartmentalising the research on consumer time rather than attempting to construct an overarching theory (Lallement and Gourmelen, 2018).

Existing research on the temporality of consumption has often been classified under two broad frameworks: one refers to universal and objective time, whereas the other refers to subjective and internalised time. The first approach stresses time as a valuable resource for consumers from the perspective of rational decision-making and time allocation theories (Lallement and Gourmelen, 2018). According to this understanding of time, linear-separable time can be divided into discrete units and allocated for actions. It proceeds as a straight line from the past to the present and into the future and is a resource comparable to money, which can be spent, saved or wasted (Graham, 1981). Consumer and marketing studies falling under this paradigm have defined time as objective, external, measurable and limited in quantity. Time can be exchanged for money or other resources to an extent, but it cannot be stockpiled or transferred to others (Becker, 1965; Feldman and Hornik, 1981; Holbrook and Lehmann, 1981; Jacoby et al., 1976; Kaufman et al., 1991; Leclerc et al., 1995; Okada and Hoch, 2004).

The more relevant approach to our study draws from the experiential research paradigm. It defines time as subjective and its perceived length may vary. Time cannot be calculated, and it is resistant to abstract generalisations; it is an individual resource and a dimension of human experience (Bergadaà, 1990; Cotte et al., 2004; Holbrook and Hirschman, 1982; Lallement and Gourmelen, 2018). Consumer time can be understood in terms of lived experience and is based on consumption tasks, events or practices (Bergadaà, 1990; Hirschman, 1987; Woermann and Rokka, 2015), which include psychological (Cotte et al., 2004; Graham, 1981; Hirschman, 1987; Hornik, 1984; Usunier and Valette-Florence, 2007), as well as social and cultural perspectives (Hirschman, 1987; Shove et al., 2009; Woermann and Rokka, 2015). The cultural perspective suggests that individuals are not limited to a single notion of time but can switch from one to another notion depending on the task at hand. For example, the circular-traditional understanding of time portrays time as comprising periodicity and repetition, as similar events tend to occur repeatedly over time. It focusses on the present and is based on natural cycles and seasons (Graham, 1981). Our study aims to contribute especially to this line of research by bridging the knowledge gap regarding recurring consumption events and examining the temporal experiences connecting such events.

In addition to social and cultural understandings of time, research conducted within the experiential paradigm includes consumers' timestyles or temporal styles, which influence how individuals react to time pressures and how they view time from their own perspective. The concept of timestyle draws from the notion of lifestyle and refers to the customary ways in which people perceive and use time based on the choices they make during everyday
Temporally recurring experiences 
QMR 24,2 activities (Feldman and Hornik, 1981). The concept was later developed by emphasising the variety of temporalities and situational frames: researchers contrasted time with metaphors such as a pressure cooker, a map that gives directions, a feedback-providing mirror, a consumer-immersing river and a feast to be enjoyed (Cotte et al., 2004).

Different timestyles describe general attitudes towards time. They tend to evolve with the person, much like their lifestyles (Usunier and Valette-Florence, 2007). Although timestyles are defined as a relatively stable characteristic of a person, they are also dynamic: they are constantly matched to the demands and expectations related to the current situation, others and the roles played by the consumer (Denton, 1994). Concepts of polychronic and monochronic time use have been used to describe individual-level characteristics or some of an individual's timestyles with respect to consumption (Kaufman et al., 1991), with the former being a valuation of how a person engages in several activities and the latter of how he/she engages in one activity at a time.

Within the experiential research paradigm, the procedural-traditional perception of time emphasises consumption activities rather than time as an external factor: it disregard the duration or passing of time and underlines procedures or practices, as well as traditions and rituals (Graham, 1981). Drawing partly from perceptions of procedural time, timeflow is a concept linking temporal experiences to consumption practices. It is defined as the temporal interrelationship between events taking place during a consumption practice (Woermann and Rokka, 2015). Based on this definition, timeflow is linked to an ongoing temporal experience of consumption practice, and it is meaningful to an individual experiencing the passage of time. Different practices, such as visiting a consumer trade show may have different timeflows regarding speed and rhythm.

While timeflow describes temporal experiences during consumption practices, the concept of timescapes emphasises the spatial features of activities from the perspective of their rhythmicities, timings and tempos, as well as their changes and contingencies (Adam, 1995, 1998; Shove et al., 2009). Timescape is a functional concept when studying consumer trade shows, as it can be used to explicate how contextual temporal practices become tangible. Temporalities and timescapes are context-generated notions, and therefore subject to constant change (Adam, 1990, 2004): they comprise tempo (speed, pace and intensity), timing (synchronisation), time point (moment, now, instant and juncture), time patterns (rhythmicity, periodicity and cyclicality) and time extensions (duration, length and continuity). An examination of timescapes adds spatiality to the understanding of temporalities in the context of consumer trade shows.

Time remains central in explaining not only a multitude of consumer behaviours but it also determines consumption in social and cultural contexts, as the reviewed literature shows. Consumer time is the central element of choice, an individual factor and the decision-making framework (Lallement and Gourmelen, 2018). Time is often perceived as an objectively measurable entity and a resource, with an emphasis on time use. It has subjective and experiential characteristics with respect to consumption. In addition, studies on an individual's views on time or personal timestyles, the cultural perceptions of time, the relationship between time and space or timescapes and temporal experiences during consumption practices, such as timeflow, have clarified the structures of consumer time. However, different temporal experiences related to recurring consumption events have scarcely been addressed in prior research. Our study extends this comprehensive body of research with the concept of a consumption timecycle, which describes the variations in temporal experiences related to repeating consumption events. 


\section{Research data and methods}

\subsection{Research context and data collection}

Our empirical research context and the site for data collection were, over three consecutive years, a local motorcycle trade show arranged by the Finnish Fair Corporation for the Motorcycles Section of the Association of Finnish Technical Traders [motorcycle trade show (MP), hereafter MP show]. The shows attracted an average of 55,000 visitors and were held in Helsinki, Finland, in the years 2014-2016. This three-day show, arranged annually on the first weekend of February since 1969, is the largest motorcycle trade show in the Nordic countries.

Consumer motorcycle trade shows represent a fruitful research case and a situational context for examining the temporality of consumption. The MP shows share elements with other similar consumption events such as motorcycle rallies (Krier and Swart, 2014), livestock trade shows and rodeos (Peñaloza, 2000, 2001), interior decoration and furniture fairs (Ahola, 2012) and international cycle shows (Andreae et al., 2013). These consumer trade shows are temporally and physically framed events that recur over time; they are repetitive and cyclical, as they take place once a year and they are distinctively built and situationally rich events that provide event-related experiences temporally distributed around a consumption event.

Most research data collection and analysis methods that investigate the characteristics of consumption experiences are qualitative and based on observation and narration (Becker, 2018; Carù et al., 2014). We used data triangulation and collected various qualitative research materials that had the potential to provide insights from several perspectives on temporal experiences during and between recurring consumption events. Our research data collection process combined observations documented in writing, recorded on video and captured in photographs, as well as the researchers' subjective introspections in the form of fieldnotes written before, during and after the shows.

Participant observation consisted of a total of seven days in the field. The fieldnotes consisted of personal reflections based on the experiences and observations of the researchers. They were compiled based on personal reflections during the observation period, at the end of each show day and as subjective reflections after the shows. Informal observation protocols were produced and memos written during breaks to systematise the observation acts. The additional research material includes $54 \mathrm{~h}$ of participant observation, $393 \mathrm{~min}$ of video recordings and 279 photographs. The photographs and video footage provided a visual record of the show space, events and visitors' activities. The video material documented the overall atmosphere of the shows and allowed us to revisit the site, its lighting, sounds and the people moving through space. The video footage helped us return to the events later and recall the associated experiences.

However, we could not observe or enter into others' experiences before, after or during the show, nor could we generalise our etic introspections or observations to cover other consumers' show experiences. It should be emphasised that our aim was not to study how visitors describe experiences at shows in their own words and from their own emic perspectives; moreover, we were not attempting to construct theoretical insights based on the experiential elements they reported sharing. Instead, our aim was to construct a consumption timecycle and associated temporalities as they emerged before the shows, at the shows and after the shows over three consecutive years, something that would otherwise be challenging to grasp.

\subsection{Data analysis}

We used an interpretive framework and in-depth exploration to better understand temporal trade show experiences (Arnould and Wallendorf, 1994; Spiggle, 1994; Thompson et al., 1989). Due to the enduring and lengthy nature of a trade show experience, we used two 
QMR 24,2

practical approaches. A consumption timecycle consists of more than just one's perceptions at the show space: show-related experiences begin to form well before entering the show's premises and do not simply stop when people leave the show area. We interpreted these preand post-show experiences by documenting personal introspections that include reflections on when and how we learned about the show, details about planning and travelling to the show site and what we felt after the show. In addition to personal introspections at the actual show event, we adopted another approach that involved observing the show's details as follows: the material, spatial and social organisations that make up the trade show.

Our approach aligns with interpreting granular and coherent consumption experiences. The former experiences are based on observation material involving situational accounts of ongoing events, whereas the latter is based on introspection, personal reflections on lived experiences and autobiographical accounts (Carù and Cova, 2008). Observations shift attention away from the self of the observer and towards the external characteristics of the situation, whereas subjective personal introspections shift attention towards the experiencers' feelings and can, therefore, be contrasted with observations. We focussed our attention particularly on temporal experiences, including pre- and post-exhibition experiences in addition to those formed during the show itself.

The research technique of personal introspection or auto-ethnography, supported other material acquired by means of observation (Gould, 1991, 2012; Hackley, 2007; Holbrook, 1995, 2006; Shankar, 2000). Introspection is useful in cases where researchers have professional knowledge of or previous experience with the subject matter and when the phenomenon under investigation is enduring or requires longitudinal examination such as the use of consumer durables or the examination of repeated consumption events (Wallendorf and Brucks, 1993). Personal introspection allows access to cognitive and sensory data regarding one's own experiences, data that cannot be obtained by other methods or from other individuals (Gould, 1995). In addition, observation methods make it possible to create detailed accounts of current environmental conditions and the actual behaviours of participants (Bitner, 1992).

From the perspective of constructing the concept of a consumption timecycle, our observations served as the source for additional propositions. Therefore, our approach of analysing personal introspections and observation material refers to "reflexivity within research" (Wallendorf and Brucks, 1993, p. 342). It answers recent calls to look into broader assemblages of consumption (Askegaard and Linnet, 2011) and "the automatic and precognitive aspects of market societies, as well as the atmospheres and affect that circulate in consumption spaces" (Hill et al., 2014, p. 390).

In practice, we produced a summary of the interpretations from the data to obtain an overview of an iterative process: we read and watched, classified and interpreted the data over several rounds. During this process, we recounted our observations and classified them into temporal themes. In other words, we classified our observations: patterns and relationships were identified amongst the data first independently and then collectively by comparing our findings. Structured researcher triangulation or comparisons of our pre- and post-show introspections, as well as the experiences induced by the showplace and space, material setting, movement and social interaction, were produced for three trade show years.

We first interpreted our introspections and observations individually and then by means of comparing them to the fieldnotes and video-recorded events. We did not attempt to explain our observations. Instead, we studied the collected material and fieldnotes, which documented what we perceived, how we felt, what made us feel the way we did and how we interpreted experiences while watching the recorded video footage afterwards. We jointly 
divided our interpretations into subcategories, while preserving what we experienced as meaningful from our individual perspectives. During the final analysis stage, we defined the characteristics of each temporal theme, described them and constructed the concept of a consumption timecycle. The findings are presented in the next section, followed by an interpretation of the temporalities that gave shape to a consumption timecycle with respect to the motorcycle show.

\section{Contextually situated and temporally recurring: constructing a consumption timecycle}

Analysis of the collected data revealed variations in temporal experiences. Although most of our experiences were connected to the main MP show events, they varied in location and extended beyond the MP show visits. The consumption timecycle of the examined shows embodied five distinct temporalities as follows: emerging, core, intensifying, fading and idletime temporalities. Our show-related experiences began when we formulated the idea of participating in the trade shows (emerging time) and changed while experiencing the main show events at the show site (core time). Occasionally, the atmosphere grew more memorable and excited (intensifying time) and slowly started to evaporate (fading time) when we returned to the everyday realm (idle time). After a year, a new rotation or turn of the timecycle started again as experiences related to participating in the forthcoming MP show or emerging time, occupied our thoughts.

\subsection{Emerging time - preparing for the consumption event}

"- Oh, you are vacuum cleaning. It has been a year, as you vacuum cleaned last time ... Oh, it is those motorcycle trade shows!" (A wife says when entering the house and noticing her husband vacuum cleaning with a suspicious face; an MP show television commercial aired in mid-January 2014 and 2015): www.youtube.com/watch?v=uz-hN4C5uYo)

One of the shared introspections based on our fieldnotes was that trade show experiences tend to be spread out over a longer period of time. The MP show consumption timecycle starts from the idea to attend the show and is repeated by resurrecting the warm feelings after another year when we begin to plan our visit to the next show. We call the temporal phase that takes place before attending a consumption event "emerging time".

Our experiences were linked to events such as planning to attend the trade show or suggesting a visit to the trade show, arranging to meet, travelling to the show venue and preparing to enter the show's premises [e.g. paying for a ticket, receiving a show catalogue, leaving our coats in the cloakroom; Figure 1(b)]. These events point to the potential for consumers to have several linked experiences or a chain of experiences before the show.

In 2014, a blizzard on the night after the first day of the show deposited more than $30 \mathrm{~cm}$ of snow [Figure 1(a)]. As documented in our fieldnotes, this caused us frustration, but while listening to a radio broadcast from the show venue we began to immerse ourselves in the show atmosphere as if we were already there.

The temporal dimension of emerging time refers to preparing for the event and making decisions such as when to participate and what to wear during the show. Peñaloza (2001) has discussed consumer performance at livestock shows, noting that the visitors' clothing was appropriate to the setting, including show specials such as cowboy hats, boots and snakeskin belts. The attire of those at the MP show followed the typical black or dark dress code of the biker and motorcycle subculture such as leather driving jackets, motorcycle brand jackets, leather and denim vests and club vests (Schouten and McAlexander, 1995). Such apparel is seldom worn outside the driving season. It indicated that the visitors had planned their participation in advance and had devoted both times and thought to such 
QMR

24,2

\section{8}

social issues as how they would appear at the show. The term trade show points to the dual role of the event: the interplay between commercial activity and subcultural meaning creation or maintenance (Andreae et al., 2013).

A temporal order shared by a social group distinguishes and separates group members from outsiders, contributes to the establishment of intergroup boundaries and constitutes a basis for mechanical solidarity within the group. The temporal coordination of complementary differences amongst group insiders enhances their interdependence and is a basis for organic solidarity within the group (Zerubavel, 1981). Emerging time is the temporal framework for making decisions related to appearances before entering the MP show. The consumer performance visible in the visitors' clothing builds a general sense of communality amongst the motorcycle enthusiasts outside the driving season while negotiating social differences within this particular subculture of consumption.

\subsection{Core time - contextually-situated temporality at the show}

In the context of the consumption timecycle, core time refers to contextually-situated temporal experiences, particularly at the show site. The trade show space, the Helsinki Exhibition and Convention Centre, is highly modifiable, but the layout of the MP show consisted of five distinct spaces that are similarly arranged every year (Figure 2). The show building has a central lobby or walkway with several entrances, exits and restaurants that divide the space and separate the show halls. Our first experiences were comparable to entering any shopping mall: crowds of people wandering in and out, echoing sounds and a gradually increasing hum while approaching the show halls, a high ceiling, stone floors, bright lighting and restaurants and cafes along the sides of the walkway (authors' fieldnotes, 2014, 2015 and 2016).

The main exhibition hall is the largest area, a well-finished and professionally designed space. It is reserved for manufacturers and distributors of new motorcycles, motorcycle brands and large accessory retailers equipped with high-quality brochures and the personnel wear matching clothing. Our impression was that the visitors to the show stayed there longest just because it was the main exhibition hall (authors' fieldnotes, 2014).

\section{Figure 1.}

Travelling to the showground was time-consuming due to the snow (left). After leaving our coats in the cloakroom, the experience of immersion intensified. The photo on the right shows the central walkway and people descending into the show experience in 2014

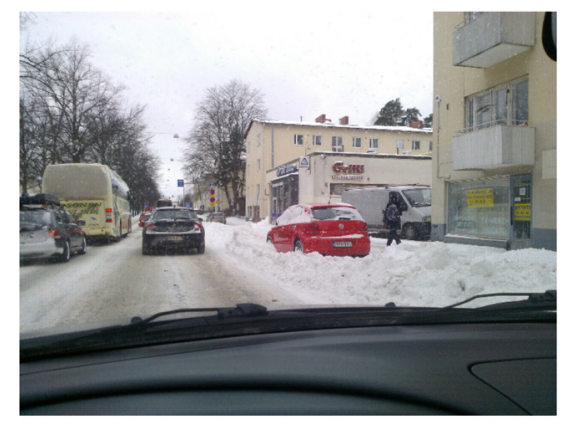

(a)

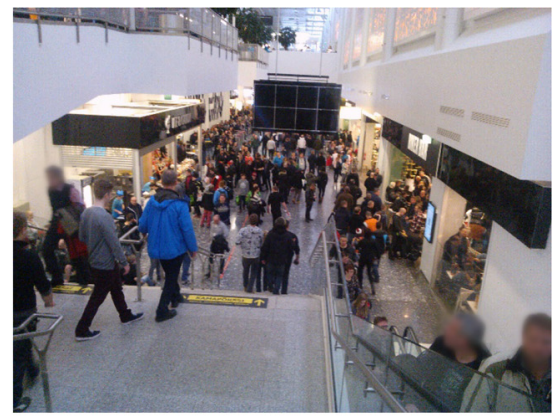

(b) 


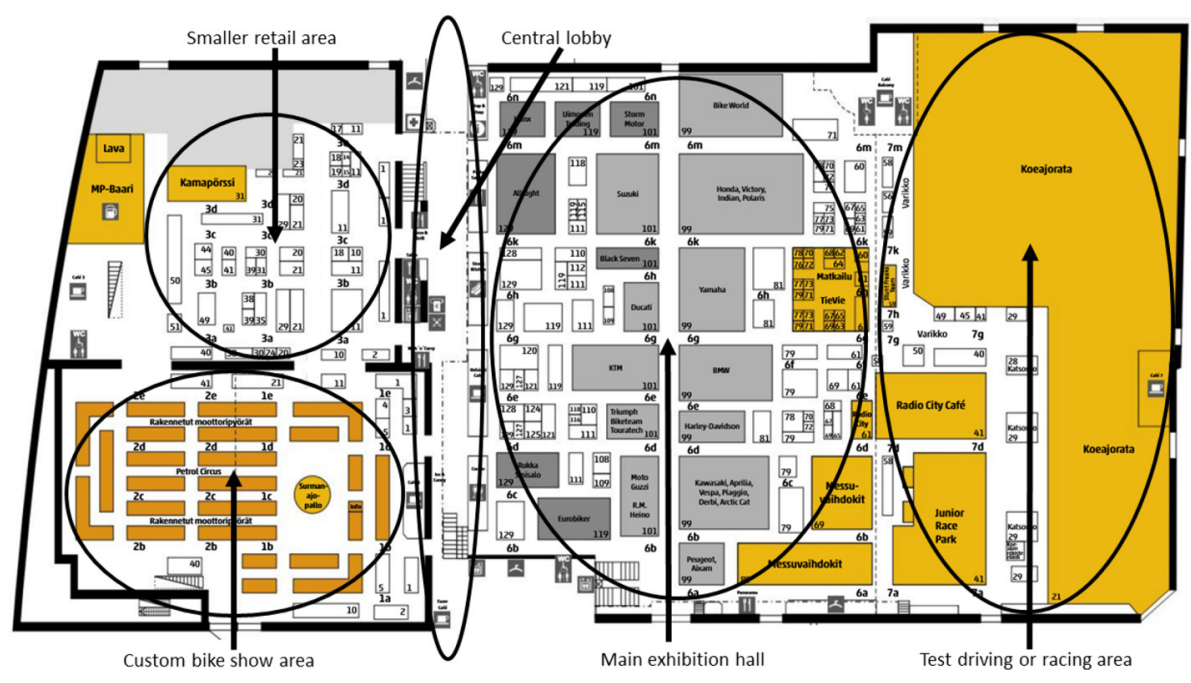

Temporally recurring experiences

229

Figure 2.

Floor plan of the Helsinki exhibition and convention centre during the MP show in 2016 (MP16 Trade

Show Magazine, 2016, pp. 26-27)

Although it varied slightly from year to year, the main exhibition hall was generally rather darkly lit, but the bikes and booths were heavily spotlighted.

The overall feeling was relaxed or softly atmospheric, as all the sounds were fainter or more muffled than those in the raw and prosaic central walkway. Furthermore, rock music and broadcasts from a local radio station could be heard, but not at a disturbingly loud volume. Consumer activities in the main show space involved looking at goods, touching and feeling merchandise and trying on accessories (authors' fieldnotes, 2014, 2015 and 2016). Andreae et al. (2013) have observed that interactions in exhibition booths, including touching and feeling products and seeing and hearing them, can seduce the consumer into a liminal space where new purchasing possibilities may be contemplated.

We concluded that the feeling of "being at the trade show" arose when we had adapted to the atmosphere in the main exhibition hall (authors' fieldnotes, 2014). In addition to the previously mentioned observations, we noticed that the notion of core time was related to the general commotion generated by crowds of people approaching from every direction, inducing an uplifting feeling that something special was really occurring. When exiting the main exhibition hall, there was clearly a sense of the "need to see, feel and experience all that was on display" (authors' fieldnotes, 2014), a characteristic typical only of the temporal experiences associated with core time.

A more low-key retail area opposite the main exhibition hall was designated for smaller companies that predominantly sold non-branded accessories and other motorcycling-related paraphernalia [Figure 3(b)]. The decoration of the space was modest, the lighting brighter and the booths smaller in comparison to the main exhibition area. Here, the sense of being at a market or a bazaar (Richardson, 1982) was tangible, comparable to that of a flea market, swap meet or garage or car boot sale (Belk et al., 1988; Sherry, 1990; Stone et al., 1996). The merchants' booths and stalls were less organised, the overall impression of the space was ragged, the lighting was bright and space was more reminiscent of an industrial hall. Visitors looked through the goods, tried to bargain with the sellers and talked to friends and other show visitors about the merchandise. In the context of flea markets, these consumer activities are referred as searching, dickering and socialisation (Sherry, 1990). 
QMR

24,2

\section{0}

Figure 3.

Viewing and examining from a distance in the custom bike area (left)

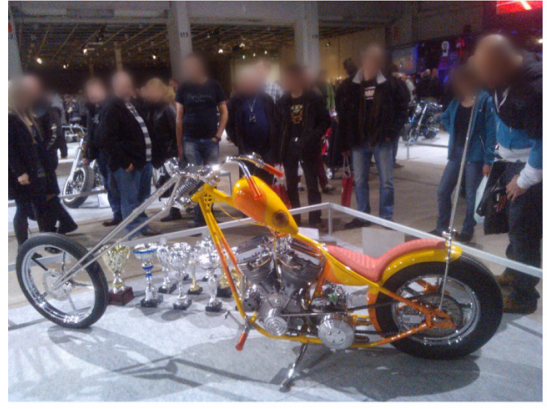

(a)

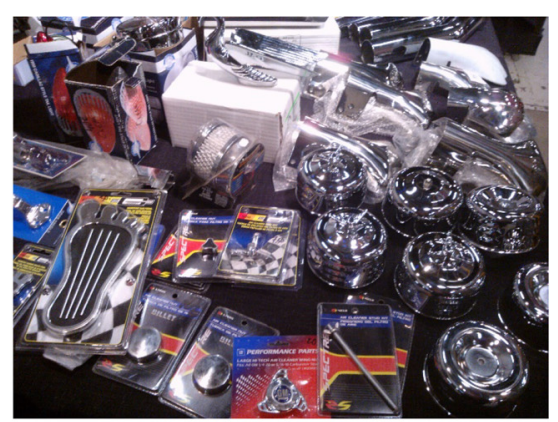

(b)

Note: Accessories available in the smaller retail area (right) in 2014

The Custom Bike Show area was offered to individual exhibitors and their custom-built motorcycles. This section was characterised by bright spotlights directed at customised bikes, guiding visitors' focus towards such unique works of craftsmanship. This space was quieter than the other show spaces. The surroundings were quite different from the main hall, which was described as being dominated by "mass-produced, generic imagery and an 'on-sale' atmosphere" (authors' fieldnotes, 2015). The hall felt spacious due to its wider aisles and significantly lower number of objects; consequently, the experience was close to that of an art exhibition. It was forbidden to touch the motorcycles, and they were fenced off from the visitors. In the custom bike area, there was an emphasis on taking photographs, discussing the exhibits and remarking on the technical and handmade characteristics of the bikes.

In the custom bike show area, we observed visitors moving slowly, taking a long, considered look at each bike, pointing with their fingers and discussing interesting technical solutions with familiar fellow visitors, and stooping down and reaching out to obtain a better view of the motorcycles (Figure 3b). Visitors engaged in short, informal conversations about the unique show bikes. The discussions documented in the fieldnotes included a lengthy conversation on "how a custom Harley-Davidson's spokes, made from a chain, could work in practice" (authors' fieldnotes, 2015) and a relaxed discussion with representatives of the Modified Motorcycle Association of Finland on "welding techniques and turbo-charging a motorcycle" (authors' fieldnotes, 2016). The customised motorcycles were not for sale, no owners or personnel were present to discuss them and the bikes and their crafted details were merely objects to admire from a distance. The custom cycles represented the unique designs, skills and lifestyles of their creators.

Another major show space was located inside a full-sized dirt track with open pitstop areas, where the official 2014 Finnish National Super Cross Championships and the 2015 World Super Enduro Championships were held during the MP shows. In 2016, a $430 \mathrm{~m}$ asphalt track was laid in this space instead of a dirt track, and visitors were offered the opportunity to test different motorcycle models for free on what was billed as Europe's longest indoor test track. The experiential atmosphere in the racetrack space meant there was little to see besides the fast-moving racing events themselves. The hall was clearly colder than the other exhibition halls, as it required more effective ventilation due to the exhaust fumes produced during the racing events. This activity-based hall dedicated to racing or test-driving motorcycles was experientially quite different from the other spaces. 
There was "a curious mix of cooking smells originating from a few booths serving food, and a smell of oil, anti-rust or solvent substances, wax and a delicate hint of exhaust fumes" (authors' fieldnotes, 2014). Similarly, the soundscape that captured the visitors' experiential world fluctuated between a steady background hum in the easy-going custom bike hall, loud announcements and rock music in the main exhibition hall and the fast-paced revving of motorcycle engines in the race hall during competitions and test drives.

The show spaces differed in their layout, but the greatest difference was in how they were set up for the visitors: the temporal experience potential with respect to core time varied significantly. The central walkway, with its restaurants and cafes, provided a space where visitors could escape the bustle of the show and enjoy food and refreshments, an important activity in consumer trade shows (Peñaloza, 2000, 2001). The main exhibition hall encouraged visitors to touch, test and sit on the show bikes and discuss purchases of motorcycles and accessories with sales personnel. The experienced temporal pace was slower. We observed that typical behaviour in the main exhibition hall included looking around or generally scanning the show space to gain an overall picture of the space. Watching is part of the trade show experience, wherein consumers actively construct cultural meanings by blending fantasy with reality as they stroll and gaze at the various elements of the show (Peñaloza, 2001).

Contextually embedded temporal experiences of core time became strikingly tangible in different spaces at the MP show when we began to analyse our written introspections and the recorded videos. However, these observations were hardly noteworthy while attending the shows as visitors. The timescapes (Adam, 1995, 1998) of the exhibition rooms varied from slow and relaxed feelings while watching details of custom bikes to the rapid tempo provided by the hectic racing events. The spatial features of the show spaces and activities involving core time experiences varied in their rhythmicities, timings and tempos.

\subsection{Interplay of intensifying and fading time}

Core time refers to the overall temporal experience of being at the show and pertains to the contextual and physical characteristics of the show site. Intensifying and fading time and the associated temporal experiences also take place at the show site, but they describe experiences of particular events that first grow intense and then ease: intensifying and fading temporal experiences tend to be interdependent.

In addition to various show spaces and encountered events at the show, temporal consumption experiences are unavoidably affected by active or passive interactions with show personnel and other visitors. Walls et al. (2011b) have suggested that these elements may include the behaviour expected of fellow visitors, respect for personal space or socioeconomic expectations. We observed that trade show encounters between old friends or colleagues, exhibitors and show site staff, were often temporally intensified, and therefore memorable (authors' fieldnotes, 2014). Another distinctive feature of trade shows has to do with walking and the flow of people. The constant, slow and relaxed stream of people plays a central role in the distinct trade show experience such as walking and moving through show spaces is the most common activity. Temporal experience intensified around the show booths and exhibits, which tended to be crowded, as visitors stopped to view and touch goods and talk with exhibitors [Figures 4(a) and 4(b)]. This seemingly acceptable form of road blocking or "posturing" (authors' fieldnotes, 2015), is temporally meaningful, as it allowed for pauses while experiences were shared between familiar visitors during such intensified moments.

We observed that the "overall immersion potential seems to evaporate slowly towards the end of the visit and when the decision to leave is made. There was first an intensifying
Temporally recurring experiences 
QMR

24,2

\section{2}

Figure 4. Intensifying time: Experimenting with motorcycles in the main exhibition hall in 2014

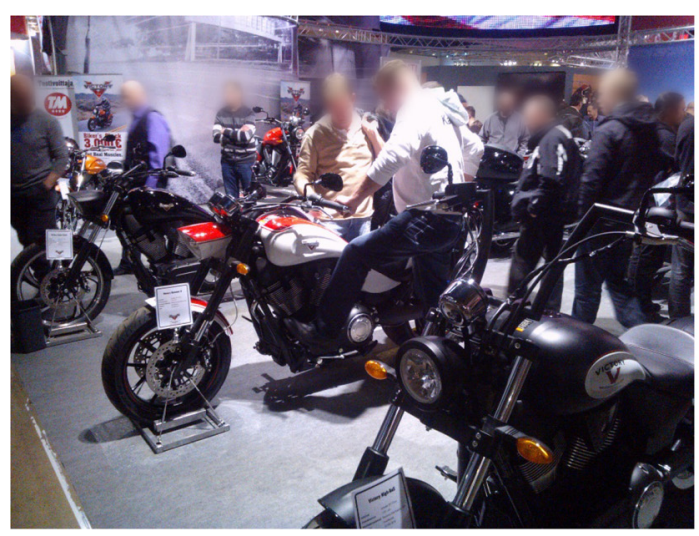

(a)

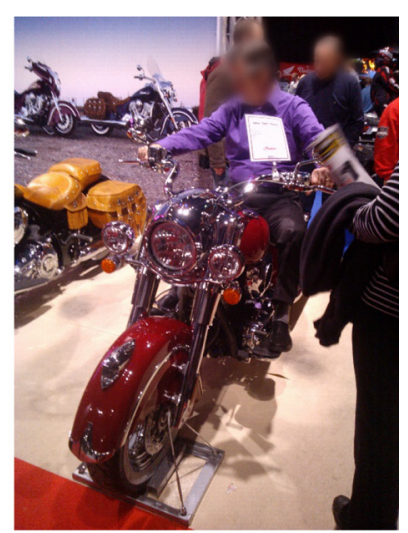

(b)

feeling that time was running out" (authors' fieldnotes, 2014). The process of immersion is the means by which consumers access and experience, which, in turn, can be total and immediate or partial and progressive (Carù and Cova, 2003, 2006, 2007; Firat and Dholakia, 1998). Immersion during consumer trade shows seems to be not only progressive and absorptive but also cyclical, as we became immersed in separate experiences numerous times during one trade show visit: intensifying and fading time describes alternating temporal experiences. Consumers typically spend several hours or a whole day at a trade show, where they encounter various experience-inducing events. We noticed that immersion levels tended to change during the visit; they affected our perception of time and were linked to sub-events experienced at the show site.

We noticed that similar feelings were experienced several times during the show, for instance when entering other show areas with novelties to observe. Time tended to pass more quickly and grow more intense when there were new things and show spaces to see. However, a sense of numbness or physical weariness was noticeable after 2 or $3 \mathrm{~h}$ of intensive walking and absorbing the bustle of the show (Ahola, 2007). Our temporal experience switched from being excited to bore, something we call fading time. Like us, other visitors carried show materials, ranging from smaller objects such as magazines and brochures to large plastic bags filled with motorcycling equipment or other motorcyclingrelated paraphernalia bought at the show. The items we had bought and were carrying around began to feel like a burden. The handles of the plastic bags dug into our hands, our legs started to feel heavier and our perception levels decreased. These feelings could easily be compared to any lengthy shopping event when temporal experiences transition from being intensifying to fading.

The final hours of the last show days had the greatest potential for bargains. The merchants slowly began to dismantle their booths and sell their stock at reduced prices. The core time phase was about to end. The remaining show visitors started to prepare to leave and the fading time associated with diminishing temporal experiences was almost tangible. The show was nearly over, and it was time to leave.

\subsection{Idle time - the period between the shows}

There is a temporal meaning for motorcyclists in the fact that the MP show is held in midwinter. It offers a commercially liminal condition, one occurring in individuals' minds 
and realised in the trade show space; it allows for threshold phases such as an anti-structure phase, which stands in contrast with structured everyday life and a sense of community shared amongst trade show visitors (Andreae et al., 2013). This transitional phase between the defined structures of everyday life and the anti-structures of the extraordinary is apparent at motorcycle trade shows, as well as in other extraordinary consumption experiences (Tumbat and Belk, 2011). In the Nordic countries, motorcycling is difficult between November and March due to cold weather, sleet and snow. The MP show is held in the middle of this winter period, and therefore it is an apt time to begin shifting one's thoughts towards motorcycling and the forthcoming spring. Experiences gained at the show are an integral part of the larger temporal order of Nordic motorcycling.

Attending an MP show in the middle of winter can be seen as a rite of passage (van Gennep, 2004) or even connected to the notion of pilgrimage discussed in the context of extraordinary consumption experiences (Tumbat and Belk, 2011). The event gathers motorcycling-minded people together to refresh their memories and orient them towards the new motorcycling season. The trade show space offers liminality to consumers in another sense: as they are temporary festivals focussed on entertainment, the MP shows provide consumers with a break from their daily routines and familiar surroundings by offering a social meeting place for enthusiasts and others interested in motorcycling. The journey to the MP show acts as part of the transition to such a liminal state and is a rite of passage not only away from everyday context but also towards the next motorcycling season.

Natural and commercial seasons alternative. When winter puts motorcycling on hold, it creates commercial opportunities for trade shows by turning the thoughts of the motorcycleminded populace to the coming summer and riding season. This larger context of seasonal variation in motorcycling is also an essential part of a consumption timecycle. An analogy between MP shows and the summer driving season can be made to seed catalogues related to the seed trade in 19th-century America: they were published in January so that plants could bloom later in the year (Moskowitz, 2009).

\section{Consumption timecycle - discussion and limitations of the study}

\subsection{Discussion}

The consumption timecycle of the MP shows extended over a certain period and consisted of pre-show experiences (emerging time), experiences during the exhibition event itself (core, intensifying and fading time) and post-show experiences (idle time). A consumption timecycle tends to repeat itself over time, but not in exactly the same manner: certain elements remain much the same such as seasonal rotation, the physical site and location, contextual settings and most of the events during the shows.

The concept of a consumption timecycle shares common elements with established conceptions of consumer time, but it is inconsistent with the temporal concepts stressing individuals' perspectives and their experiences. Complex characteristics of consumer time tend to escape an overarching theory construction (Lallement and Gourmelen, 2018). This also applies in the case of the consumption timecycle.

Objective time is represented in the fixed organising dates of the MP show, is an annual event open to the public for just three days. Time, understood as objective or based on a linear-separable model, frames the potential for core, intensifying and fading temporal experiences taking place at the show venue. A consumption timecycle also refers to the subjective nature of temporal experiences, which are formed in the interplay of the objective passing of time and subjective temporal experiences and based on consumption events and practices (Bergadaà, 1990; Hirschman, 1987; Woermann and Rokka, 2015).
Temporally recurring experiences 
QMR 24,2

\section{4}

A consumption timecycle has a temporal starting point in the past, something that can be relived only in one's memories. At the same time, it is assumed that consumption events and their characteristics will be repeated in the future. Experiences related to a consumption timecycle evolve, as the awaited future event will be somewhat different. This refers to the cyclical conception of time based on periodicity, repetition and seasons (Graham, 1981).

The procedural-traditional perception of time (Graham, 1981), and to a certain extent the concept of timeflow (Woermann and Rokka, 2015), both refer to the present and emphasise consumption activities and temporal experiences during consumption practices rather than time as an external factor. These concepts are useful in describing particular consumption events and consumer experiences in detail, whereas the concept of a consumption timecycle extends the focus beyond a singular event or an individual consumer's perceptions. According to our observations, a consumption timecycle covers several temporalities and contexts of repeating consumption events. For similar reasons, the concept of a consumption timecycle is less applicable in cases where the aim is to describe an individual consumer's timestyles or temporal styles (Cotte et al., 2004; Feldman and Hornik, 1981; Usunier and Valette-Florence, 2007), requiring detailed analysis from an individual's perspective.

The consumption timecycle shares common elements with the concept of timescapes, which emphasise the spatial features of activities from the perspective of their rhythmicities, timings and tempos, as well as their changes and contingencies (Adam, 1995, 1998; Shove et al., 2009). When considering the show events and spaces, it is evident that the various showrooms and events had clearly differing rhythms and tempos that affected our temporal experiences. Although the concept of timescapes aligns well with the observations made during the show events at the site, it is challenging to apply it to pre- and post-show experiences or to phenomena taking place outside the show's premises. These include the meanings of the winter season in motorcycling, the cyclical nature of the MP shows or other similar consumption events and consumers' preparations for the show before attending.

We based our construction of the concept of a consumption timecycle on observations made about the key temporalities (described in Figure 5). In the examined case, the duration of the consumption timecycle is about one year. The length can vary depending on an examined consumption event and its repetition frequency. An examination can start from any point in the cycle. We observed that having the idea to participate, planning the trip, travelling and entering the show's premises were all events that induced experiences, something that has not been touched on in the extant research. These temporally situated experiences or what we call emerging time, are meaningful for consumers preparing to participate in a consumption event.

By core time, we refer to temporal experiences that took place during the MP show events and at the show site. The period for these experiences was restricted in our case to three-show days when the key events regarding the timecycle took place. We noted that intensifying and fading time were interdependent and took place mostly at the show site and in relation to experienced events. Although these two temporalities can be associated with pre-show (or emerging time) and post-show (or idle-time) experiences, we observed that experiences of intensifying and fading time take place more clearly in connection with experiences at the show site. We associated intensifying time with uplifting experiences while participating in various sub-events at the shows, induced by the different layouts of the show spaces offering novel things to see and the social sphere or interactions with both show personnel and other visitors. Fading time emerged when the experiences of engagement, enthusiasm and immersion gradually gave way to physical weariness and boredom regarding singular show events but also in general towards the end of the show visit. 


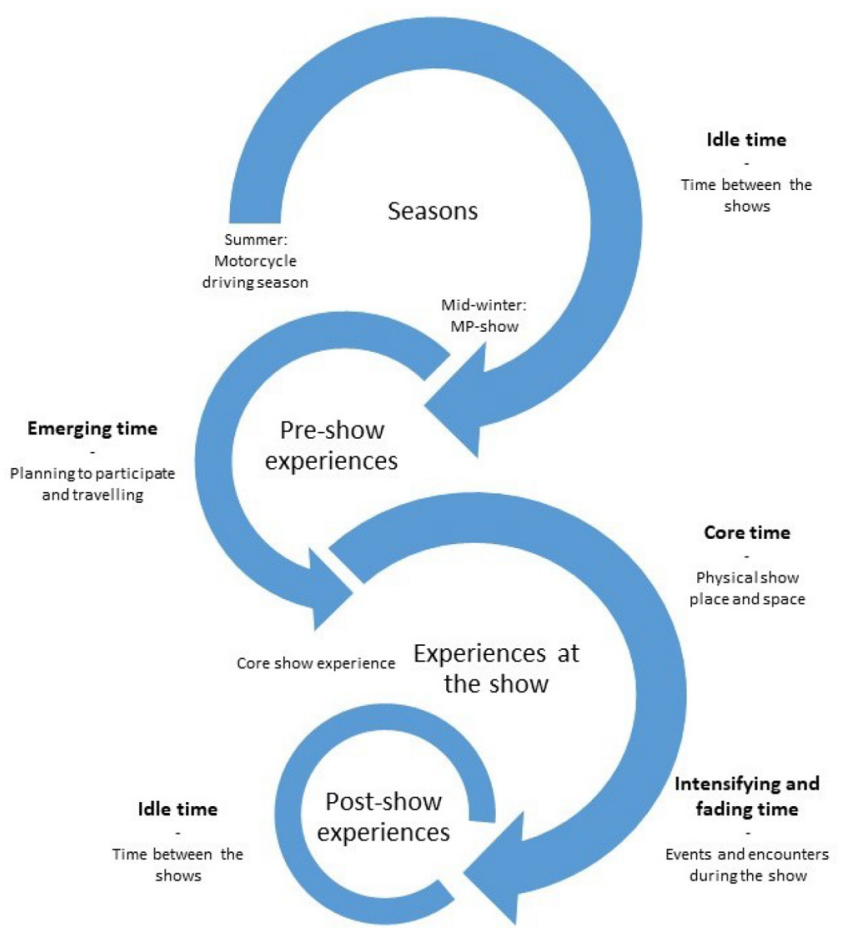

Temporally recurring experiences

Idle time refers to post-show experiences taking place after the shows or between the end of a consumption event and the beginning of emerging time. During this temporal frame, experiences regarding the bygone consumption event are randomly recalled and, when enough time has passed, even forgotten or no longer actively thought about. A new rotation of a consumption timecycle begins at the end of the idle period: emerging time steps in and the upcoming MP show occupies the mind of a potential show visitor. The promise of breaking out of familiar routines and the flow of everyday life is offered all over again for participants in this particular subculture of consumption: arranged in the middle of wintertime, the MP show represents a liminal condition and a symbolic transition to a hobby or lifestyle that has been temporarily put on hold. By starting a new cycle, emerging time represents an opportunity for a symbolic rite of passage to a driving season that is soon to arrive.

\subsection{Limitations of the study}

Some of the limitations of the present study stem from general challenges in studying temporal experiences, while others are specific to our particular research design. We noticed that singular experiences often eclipsed the ongoing stream of experience at the shows. Although we strove to grasp the central temporal elements of consumption, our examination tended to revolve around special moments perceived and remembered one after the next. This is also a major challenge in research cases using consumer-generated research materials.

It is difficult or even impossible to have experience and simultaneously reflect on the meanings of that experience. Therefore, research materials on temporal experiences are always mediated. Consequently, our examination is partly dependent on memories. 
QMR

24,2

Although video, photograph and fieldnote material helped to refresh our memories and allowed us to return to the events and surroundings at the trade show, it should be noted that the experiences evoked while watching video footage or reading fieldnotes regarding show experiences are not the same as the actual lived experiences.

People can later recall the specific details of a consumption event. This will re-shape the lived experiences, as memory is a subjective and selective device for recording the past. Experiences are not stable once the events encountered at a trade show are over and the consumers have transitioned back to their everyday lives. Thus, we suggest that there is no single, consistent experience or even class of experiences. Instead, there are bundles of consumption experiences connected to a temporally structured consumption event. These temporal experiences are not fixed; rather, they change as they are remembered and reflected upon.

The examination of our observation and introspection material produced somewhat different outcomes due to their different perspectives. The use of introspective methods has been controversial. The best access to any experience or series of experiences resides with the subjects who have lived the events and felt the related experiences. This is the primary reason why we chose an etic approach. Our etic introspections do not describe other consumers' experiences. Our approach nevertheless allowed us to immerse ourselves in situated experiences encountered before, during and after the MP show events. This made it possible to reflect on the longitudinally temporal aspects of a repeating consumption event and to construct the concept of a consumption timecycle.

In addition, a potential limitation is that our case, the MP shows we observed, took place in the Nordic context. Therefore, the transferability of the results to different trade shows arranged in other places might be limited. The emic construction of the concept of a consumption timecycle is also based on our observations and introspection in this specific context. However, consumer trade shows are international in nature and the concepts regarding temporal experiences tend to be universal. Extant research findings of consumer time align with the consumption timecycle regarding general conceptions of time such as cyclical time and timescapes, but less so in the contexts requiring individual perspectives such as timestyles or timeflow. However, the consumption timecycle is a flexible concept that makes it possible to describe seasonal, cyclical or repeating consumption events and the time between these events more holistically than other concepts of consumer time.

Future research on the consumption timecycle should be conducted in a variety of contexts to allow for a better understanding of cultural differences and meanings. Studies on the experiential domain have called for context-specific inquiries to increase knowledge about consumption. Consumption events have various rhythms, tempos and frequencies, which call for longitudinal research in other repeating consumption events. Therefore, the concept of a consumption timecycle should be used in other consumption contexts with reservation. The concept of a consumption timecycle extends the discussions about consumer time and temporal consumption experiences, encouraging us to seek novel approaches to the stream of viable and evolving research on consumer time.

\section{References}

Adam, B. (1990), Time and Social Theory, Polity Press, Cambridge.

Adam, B. (1995), Timewatch: The Social Analysis of Time, Polity Press, Cambridge.

Adam, B. (1998), Timescapes of Modernity: The Environment and Invisible Hazards, Routledge, London.

Adam, B. (2004), Time, Polity Press, Cambridge. 
Ahola, E.K. (2007), "Producing experience in marketplace encounters: a study of consumption experiences in art exhibitions and trade fairs", $\mathrm{PhD}$ thesis, Helsinki School of Economics, available at: epub.lib.aalto.fi/pdf/diss/a299.pdf

Ahola, E.-K. (2012), "Towards an understanding of the role of trade fairs as facilitators of consumer creativity", Journal of Marketing Communications, Vol. 18 No. 5, pp. 321-333.

Andreae, M., Hsu, J.-Y. and Norcliffe, G. (2013), "Performing the trade show: the case of the Taipei international cycle show", Geoforum, Vol. 49, pp. 193-201.

Arnould, E. and Wallendorf, M. (1994), "Market-oriented ethnography: interpretation building and marketing strategy formulation", Journal of Marketing Research, Vol. 31 No. 4, pp. 484-504.

Askegaard, S. and Linnet, J. (2011), "Towards an epistemology of consumer culture theory: phenomenology and the context of context", Marketing Theory, Vol. 11 No. 4, pp. 381-404.

Becker, G.S. (1965), "A theory of the allocation of time”, The Economic Journal, Vol. 75 No. 299, pp. 493-517.

Becker, L. (2018), "Methodological proposals for the study of consumer experience", Qualitative Market Research: An International Journal, Vol. 21 No. 4, pp. 465-490.

Belk, R., Sherry, J. Jr. and Wallendorf, M. (1988), "A naturalistic inquiry into buyer and seller behavior at a swap meet”, Journal of Consumer Research, Vol. 14 No. 4, pp. 449-470.

Bergadaà, M.M. (1990), "The role of time in the action of the consumer", Journal of Consumer Research, Vol. 17 No. 3, pp. 289-302.

Bergadaà, M.M. (2007), "Temporal frameworks and individual cultural activities. Four typical profiles", Time and Society, Vol. 16 Nos 2/3, pp. 387-408.

Bitner, M. (1992), "Servicescapes: the impact of physical surroundings on customers and employees", Journal of Marketing, Vol. 56 No. 2, pp. 57-71.

Carù, A. and Cova, B. (2003), "Revisiting consumption experience: a more humble but complete view of the concept", Marketing Theory, Vol. 3 No. 2, pp. 267-286.

Carù, A. and Cova, B. (2006), "How to facilitate immersion in a consumption experience: appropriation operations and service elements", Journal of Consumer Behaviour, Vol. 5 No. 1, pp. 4-14.

Carù, A. and Cova, B. (2007), "Consumer immersion in an experiential context", in Carú, A. and Cova, B. (Eds), Consuming Experience, Routledge, London, pp. 34-47.

Carù, A. and Cova, B. (2008), "Small versus big stories in framing consumption experiences", Qualitative Market Research: An International Journal, Vol. 11 No. 2, pp. 166-176.

Carù, A., Cova, B. and Pace, S. (2014), "Combining qualitative methods in practice: a contextualized account of the evolution of consumer studies", Management Decision, Vol. 52 No. 4, pp. 777-793.

Cotte, J., Ratneshwar, S. and Mick, D.G. (2004), "The times of their lives: phenomenological and metaphorical characteristics of consumer timestyles", Journal of Consumer Research, Vol. 31 No. 2, pp. 333-345.

Denton, F. (1994), "The dynamism of 'personal' timestyle: how we do more in less time", Advances in Consumer Research, Vol. 21 No. 1, pp. 132-136.

Feldman, L.P. and Hornik, J. (1981), "The use of time: an integrated conceptual model”, Journal of Consumer Research, Vol. 7 No. 4, pp. 407-419.

Firat, F. and Dholakia, N. (1998), Consuming People: From Political Economy to Theatres of Consumption, Routledge, London.

Gould, S. (1991), "The self-manipulation of my pervasive, perceived vital energy through product use: an introspective-praxis approach”, Journal of Consumer Research, Vol. 18 No. 2, pp. $194-207$.

Gould, S. (1995), "Researcher introspection as a method in consumer research: applications, issues, and implications", Journal of Consumer Research, Vol. 21 No. 4, pp. 719-722.

Gould, S. (2012), "The emergence of consumer introspection theory (CIT): introduction to a JBR special issue", Journal of Business Research, Vol. 65 No. 4, pp. 453-460. 
QMR 24,2

Graham, R.J. (1981), "The role of perception of time in consumer research", Journal of Consumer Research, Vol. 7 No. 4, pp. 335-342.

Hackley, C. (2007), "Auto-ethnographic consumer research and creative non-fiction. Exploring connections and contrasts from a literary perspective", Qualitative Market Research: An International Journal, Vol. 10 No. 1, pp. 98-108.

Hill, T., Canniford, R. and Mol, J. (2014), "Non-representational marketing theory”, Marketing Theory, Vol. 14 No. 4, pp. 377-394.

Hirschman, E.C. (1987), "Theoretical perspectives of time use: implications for consumer behavior research", in Sheth, J.N. and Hirschman, E. (Eds), Research in Consumer Behavior, JAI Press, Hirschman, Greenwich, CT, pp. 55-82.

Holbrook, M. (1995), "Consumer research”, Introspective Essays on the Study of Consumption, Sage, Thousand Oaks.

Holbrook, M. (2006), “Consumption experience, customer value, and subjective personal introspection: an illustrative photographic essay", Journal of Business Research, Vol. 59 No. 6, pp. 714-725.

Holbrook, M. and Hirschman, E.C. (1982), "The experiential aspects of consumption: consumer fantasies, feelings, and fun”, Journal of Consumer Research, Vol. 9 No. 2, pp. 132-140.

Holbrook, M.B. and Lehmann, D.R. (1981), "Allocating discretionary time: complementarity among activities", Journal of Consumer Research, Vol. 7 No. 4, pp. 395-406.

Hornik, J. (1984), "Subjective vs objective time measures: a note on the perception of time in consumer behavior", Journal of Consumer Research, Vol. 11 No. 1, pp. 615-618.

Jacoby, J., Szybillo, G.J. and Berning, C.K. (1976), “Time and consumer behavior: an interdisciplinary overview”, Journal of Consumer Research, Vol. 2 No. 4, pp. 320-339.

Kaufman, C.F., Lane, P.M. and Lindquist, J.D. (1991), "Exploring more than 24 hours a day: a preliminary investigation of polychronic time use", Journal of Consumer Research, Vol. 18 No. 3, pp. 392-401.

Krier, D. and Swart, W. (2014), "The commodification of spectacle: spectators, sponsors and the outlaw biker diegesis at sturgis", Critical Sociology, Vol. 42 No. 1, pp. 11-32.

Lallement, J. and Gourmelen, A. (2018), "The time of consumers: a review of researches and perspectives", Recherche et Applications en Marketing (English Edition), Vol. 33 No. 4, pp. 92-126.

Leclerc, F., Schmitt, B.H. and Dubé, L. (1995), "Waiting time and decision making: is time like money?”, Journal of Consumer Research, Vol. 22 No. 1, pp. 110-119.

Lindberg, F. and Østergaard, P. (2015), "Extraordinary consumer experiences: why immersion and transformation cause trouble", Journal of Consumer Behaviour, Vol. 14 No. 4, pp. 248-260.

Lindberg, F. and Eide, D. (2016), "Challenges of extraordinary experiences in the arctic", Journal of Consumer Behaviour, Vol. 15 No. 1, pp. 15-27.

Moskowitz, M. (2009), "Calendars and clocks: cycles of horticultural commerce in nineteenth-century America", in Shove, E., Trentmann, F. and Wilk, R.R. (Eds), Time, Consumption and Everyday Life: Practice, Materiality and Culture, Berg, Oxford, pp. 115-128.

MP16 Trade Show Magazine (2016), “Official MP-show magazine”, Messukeskus, Helsinki, available at: https://issuu.com/messukeskus/docs/mp16_messulehti_084b92e6806814

Okada, E.M. and Hoch, S.J. (2004), "Spending time versus spending money", Journal of Consumer Research, Vol. 31 No. 2, pp. 313-323.

Peñaloza, L. (2000), "The commodification of the American west: marketers' production of cultural meanings at the trade show", Journal of Marketing, Vol. 64 No. 4, pp. 82-109.

Peñaloza, L. (2001), "Consuming the American west: animating cultural meaning and memory at a stock show and rodeo", Journal of Consumer Research, Vol. 28 No. 3, pp. 369-398.

Richardson, M. (1982), "Being-in-the-market versus being-in-the-plaza: material culture and the construction of social reality in Spanish America", American Ethnologist, Vol. 9 No. 2, pp. 421-436. 
Schouten, J. and McAlexander, J. (1995), "Subcultures of consumption: an ethnography of the new bikers", Journal of Consumer Research, Vol. 22 No. 1, pp. 43-61.

Shankar, A. (2000), "Lost in music? Subjective personal introspection and popular music consumption", Qualitative Market Research: An International Journal, Vol. 3 No. 1, pp. 27-37.

Temporally recurring experiences

Sherry, J. Jr (1990), “A sociocultural analysis of a midwestern American flea market”, Journal of Consumer Research, Vol. 17 No. 1, pp. 13-30.

Shove, E., Trentmann, F. and Wilk, R. (Eds) (2009), Time, Consumption and Everyday Life: Practice, Materiality and Culture, Berg, Oxford.

Spiggle, S. (1994), "Analysis and interpretation of qualitative data in consumer research", Journal of Consumer Research, Vol. 21 No. 3, pp. 491-503.

Stone, J., Horne, S. and Hibbert, S. (1996), "Car boot sales: a study of shopping motives in an alternative retail format", International Journal of Retail and Distribution Management, Vol. 24 No. 11, pp. 4-15.

Thompson, C., Locander, W. and Pollio, H. (1989), "Putting consumer experience back into consumer research: the philosophy and method of Existential-Phenomenology", Journal of Consumer Research, Vol. 16 No. 2, pp. 133-146.

Tumbat, G. and Belk, R. (2011), "Marketplace tensions in extraordinary experiences", Journal of Consumer Research, Vol. 38 No. 1, pp. 42-61.

Usunier, J.C. and Valette-Florence, P. (2007), "The time styles scale: a review of developments and replications over 15 years", Time and Society, Vol. 16 No. 2-3, pp. 333-366.

van Gennep, A. (2004), The Rites of Passage, Routledge, London.

Wallendorf, M. and Brucks, M. (1993), "Introspection in consumer research: implementation and implications", Journal of Consumer Research, Vol. 20 No. 3, pp. 339-359.

Walls, A., Okumus, F., Wang, Y. and Kwun, D.J.-W. (2011a), “An epistemological view of consumer experiences”, International Journal of Hospitality Management, Vol. 30 No. 1, pp. 10-21.

Walls, A., Okumus, F., Wang, Y. and Kwun, D.J.-W. (2011b), "Understanding the consumer experience: an exploratory study of luxury hotels", Journal of Hospitality Marketing and Management, Vol. 20 No. 2, pp. 166-197.

Woermann, N. and Rokka, J. (2015), "Timeflow: How consumption practices shape consumers' temporal experiences", Journal of Consumer Research, Vol. 41 No. 6, pp. 1486-1508.

Zerubavel, E. (1981), Hidden Rhythms. Schedules and Calendars in Social Life, University of CA Press, Berkeley.

\section{Corresponding author}

Toni Ryynänen can be contacted at: toni.ryynanen@helsinki.fi

For instructions on how to order reprints of this article, please visit our website:

www.emeraldgrouppublishing.com/licensing/reprints.htm

Or contact us for further details: permissions@emeraldinsight.com 